\title{
Motivating propositional gratitude
}

\author{
Michael Rush ${ }^{1}$
}

Published online: 23 January 2019

(C) The Author(s) 2019

\begin{abstract}
The discussion of propositional gratitude stands in need of a secure theoretical underpinning. Its place in the gratitude literature, alongside the more familiar targeted gratitude that we direct towards benefactors, now seems assured, but its adoption has been uncritical in many cases. In this paper, I argue that existing accounts of gratitude fail to give us good reason to incorporate propositional gratitude into our theories. I discuss Sean McAleer's paper 'Propositional Gratitude' (Am Philos Q 49:55-66, 2012) in some detail, and argue that the connection he draws between propositional gratitude and humility is not as close as he supposes, and cannot do all the work required of it. Then I trace the connections between propositional gratitude, targeted gratitude, and gladness, and develop and defend a definition of gratitude that integrates the propositional and the targeted components.
\end{abstract}

Keywords Propositional gratitude $\cdot$ Targeted gratitude $\cdot$ Gladness · Emotion

The concept of propositional gratitude-gratitude that such-and-such is the case, rather than gratitude directed to a perceived benefactor-was historically neglected, but is enjoying increasing and deserved recognition. There is a growing consensus that propositional gratitude really is a kind of gratitude alongside the more familiar agent-directed form, that psychologists can design experiments to test for it, and that theories of gratitude must take account of it. Unfortunately, the situation has shifted from under-motivated neglect to under-motivated inclusion. Propositional gratitude is beginning to occupy its justified central place in the discussion and this change is for the better, but it won't do unless we can put it on some firmer footing.

Michael Rush

m.d.rush@bham.ac.uk

1 Department of Philosophy, ERI Building, University of Birmingham, Edgbaston B15 2TT, UK 
Attempts are now being made to correct this. After some background in Sect. 1, in Sect. 2 I address in detail the first and in some ways most promising of these defences, due to McAleer (2012). Having shown that McAleer's defence of propositional gratitude is inadequate, in Sect. 3 I distinguish propositional gratitude from an emotional response I will call 'gladness'. This is a crucial distinction for any theory of propositional gratitude to honour since otherwise it is hard to defend against the view that we already have the theoretical machinery to do what propositional gratitude is being presented as uniquely capable of doing. In some contexts propositional gratitude and gladness turn out to give us different results with counterfactuals. I end by defending a new definition of gratitude that gives a central place to propositional gratitude, indeed which makes it more basic than targeted gratitude, and necessary before targeted gratitude is possible. ${ }^{1}$ I close with a discussion of why each clause of the definition is necessary.

\section{Background to the debate}

The discussion of gratitude has come to be framed in terms of dyadic and triadic accounts, according to whether the theory takes gratitude to require a triadic relation between a benefit, a beneficiary, and a benefactor, or it allows that gratitude can be present given a dyadic relation between a beneficiary and a benefit, in the absence of a benefactor. Since no dyadic conception of gratitude exists that doesn't also recognise the triadic conception of gratitude, and my account is no exception, for convenience I'll talk in terms of dyadic and triadic components of gratitude rather than dyadic and triadic accounts or definitions. The dyadic component we will call 'propositional gratitude' and we will style it gratitude that $x$, and say that a person, $p$, in the relevant circumstances is grateful that $x$; the triadic component we will call 'directed' or 'targeted' gratitude, or gratitude to a (for $x)^{2}$

Gratitude to a for $x$ involves a three-place relation. I will understand this relation as follows: the grateful person, $p$, is grateful to someone, $a$, who is judged by $p$ to have been responsible, without a disqualifying negative attitude or intention, for something, $x$, that is judged by $p$ to have been of benefit to $p$. The details will be clarified later on, but a word is in order on disqualifying negative attitudes and

\footnotetext{
${ }^{1}$ My definition will take targeted gratitude as explanatorily more basic than propositional gratitude, because it is by far the better-understood of the two. An equivalent definition is possible without making this move, but it would be rather longer-winded. Propositional gratitude is metaphysically more basic inasmuch as it can exist on its own, while every instance of targeted gratitude is grounded in an instance of propositional gratitude.

${ }^{2} x$, here, is a state of affairs. Or more neutrally $x$ is something that is the case. Rather than ' $p$ is grateful to $a$ (for $x$ )' I could have used a different formulation that made the nature of $x$ a little more explicit, for example ' $p$ is grateful to $a$ for making it the case that $x$ ', but there are two reasons against this. First, the convenience of following the formulation used by McAleer (2012: 55). Second, and more importantly, my claim will be that targeted gratitude requires that $p$ believe that $a$ made it the case that $x$, but not that $a$ in fact made it the case that $x$, and the formulation I adopt here removes one possibility of confusion on that point. The parentheses round 'for $x$ ' are there only to highlight the fact that in common usage the whole thing is often shortened to sentences of the form, ' $p$ is grateful to $a$ ', with the nature of the perceived benefit left unspecified.
} 
intentions. The point is just that you would appropriately fail to be grateful to someone who had set out to harm you even if their actions resulted in something you judged to be of benefit to you. For instance, I would benefit from someone's pushing me out of the path of a falling grand piano even when they did it as part of a botched attempt to shove me down a well. I would not, except perhaps ironically, send them a thank you letter.

The claim here is stronger than it might seem. I do not want to say that, though I may not be grateful to this person under the description "person who attempted to push me down a well', nevertheless I am grateful to them under the description 'person who saved me from being crushed by a piano'. I want to say that the fact that they were trying to kill me means I am not grateful to them at all, even for positive direct consequences of their efforts on my life. What I am is grateful that they saved my life. I don't deny that there is a response of gratitude in this case, I only say that it is a mistake to think of it as properly directed at my assailant. The possibility of propositional gratitude can save the important parts of our gratitude intuitions here. More on disqualifying negative attitudes in Sect. 3.3, below. ${ }^{3}$

The relation involved in gratitude that $x$ is essentially two-place: a person, $p$, is grateful that such-and-such, $x$, is the case. Whenever $p$ is grateful to $a$ for $x, p$ is also grateful that $x$. Where no agent is identified as the author of $x, p$ may still be grateful that $x$. There may or may not have actually been any agent responsible for $x$, and $p$ may or may not come to realise this later. Moreover, propositional gratitude can help to explain situations in which there is both a benefit and an agent but in which one is not grateful to the agent for bringing about the benefit, such as the grand piano case: I am grateful that I have been pushed out of the path of a falling piano, but not grateful to the agent responsible, owing to their malicious intentions.

In cases of directed gratitude, the thing for which one is grateful may be the bringing about of $x$, the attempt to bring it about that $x$, the demonstration of love embodied in the failed attempt to help, etc. If the attempt fails you don't get the benefit that your would-be benefactor was aiming at, but provided the attempt wasn't a case of meddling, or sabotage, or any such thing, you may be grateful for the gesture of solidarity or the expression of empathy. The class of benefits is broad enough to include counting someone as having benefited you by trying and failing to fix your washing machine provided you hadn't expressly asked them not to, they weren't doing it to show off as a way of undermining your confidence, or your credibility in front of your family, or anything of that sort. ${ }^{4}$ If I am grateful to you for retrieving my kite from a tree, I am grateful that my kite is retrieved. If I believe that no agent was involved in getting my kite down from the tree, I am grateful that my kite is down from the tree. The test for whether one is grateful that $x$ in cases that lack an agent to be a benefactor is to see whether one would have been grateful to an agent that one took to be such a benefactor, and that one took to have acted without malice or other negative attitude that would have stopped one's gratitude to them in its tracks.

\footnotetext{
3 Thank you to an anonymous referee for their comment on this point.

4 Thanks to Ema Sullivan-Bissett for suggesting this clarification.
} 
The motivation for thinking that in cases lacking a benefactor one can be grateful that $x$, as distinct from merely glad that $x$, is that a systematic distinction can be drawn between cases in which one would have been grateful to an agent that brought about $x$, and cases in which one would not. In other words, those cases you take to be a benefit to you personally but that you take to lack a benefactor, and those cases towards which you have a positive attitude, inclination, or emotional reaction but which you don't take to be of benefit to you personally. This will be spelt out in more detail in Sect. 3.

I will argue that propositional gratitude is founded on an appropriate sort of positive emotional response to one's circumstances, giving rise in certain conditions to gratitude-that such-and-such is the case, and that directed gratitude augments this propositional form in some but not all cases.

McAleer wrote that 'contemporary authors [treat] propositional gratitude (A's being grateful that $\mathrm{p}$ ) [...] as a poor, less interesting cousin of [targeted gratitude (A's being grateful to B for x)] when [they treat] it at all' (McAleer 2012: 55). McAleer notes one exception in Walker (1981), who distinguishes between gratitude and gratefulness, where the latter is supposed to be, roughly, gratitudethat and the former gratitude-to. Walker says that since 'gratefulness need not always be "focused" on another person, does not always have to be gratefulness to someone [...] cases of gratefulness cannot always be cases of gratitude' (Walker 1981: 45). Claudia Card acknowledges that gratitude not to someone, though still for something, may be legitimate (Card 1988: 117). Patrick Boleyn-Fitzgerald also seems to take seriously the possibility of exhibiting Walker-style gratefulness but not gratitude, though his argument, he says, appeals only to the latter (Fitzgerald 1998: 146-149). In Boleyn-Fitzgerald (2016) he takes it for granted that propositional gratitude is a genuine phenomenon, but argues that it lacks some of the beneficial features of targeted gratitude.

In the recent philosophy and psychology literatures we find interesting new contributions to existing discussions, and the framing of new branches of the debate. $^{5}$ The psychology literature can seem to be characterised by a reluctance to define its terms: assumptions are often made about the nature of gratitude before using those assumptions to design instruments to test for it. Kristján Kristjánsson bemoans the fact that "philosophers engaged in the gratitude discourse typically seem to take themselves to be analysing the umbrella concept when they are, in fact, simply analysing a specific sub-concept of gratitude [...]. The psychologists, on the other hand, seem to be genuinely lost as to what type of concept they are applying and measuring. Hence, they simply pluck some standard definition out of the air and posit that as the characterisation of 'the concept of gratitude"' (Kristjánsson 2015: 503). My aim here is to present an account of gratitude in which every aspect is

\footnotetext{
5 To get a sense of the debate and its history see for instance Seneca (2001, 2006), Aquinas (1964), Hobbes (1998), Kant (1967, 2000), Nietzsche (1994), Paley (1822), Hewitt (1924), Stout (1927), Lyons (1969), Strawson (1974), Berger (1975), Simmons (1979), Walker (1981, 1988, 1989), Klosko (1989, 1991), Swinburne (1989), McConnell (1993), Wellman (1999), Knowles (2002), Von Tevenar (2006), Carr (2013, 2016), Gulliford et al. (2013), Shaw (2013), Berkovski (2014), Roberts (2014) and Kristjánsson (2015).
} 
given a principled defence. This account could later form the basis of psychological investigations.

One point from the psychology literature is worth addressing in this paper as it bears directly on the distinction I want to draw between propositional gratitude and gladness. Kristjánsson (2015), drawing on his joint work in Gulliford et al. (2013), suggests that when one is tempted to defend the possibility of dyadic gratitude, which is to say gratitude lacking a benefactor as its target, what one really has is a case of what Adler and Fagley (2005) call 'appreciation'. Gladness and propositional gratitude together can account for the cases in which Kristjánsson sees appreciation at play; a good many of those cases turn out to be cases of gratitude in virtue of being cases of propositional gratitude, and indeed all the cases that Kristjánsson and everyone else takes to be uncontroversial examples of (triadic) gratitude are accompanied by propositional gratitude in a clear and systematic way. Once we are not distracted by the need to conform to an existing theory of humility (McAleer 2012) or justice (Fitzgerald 1998), or the desire to frame an Aristotelian virtue (Kristjánsson 2015), there is no need to artificially keep the supposed subconcepts apart: they can be brought under a single definition.

McAleer's (2012) embodies an attempt to defend propositional gratitude against widespread indifference or hostility. His "primary claim [...] is that propositional gratitude is morally important because of its conceptual connections to humility, an important moral virtue.' He goes on, '[an] implication of this is that targeted gratitude to nonagents is likewise coherent and morally important when it expresses humility, which shows that a widely held claim about gratitude is false' (2012: 55).

The widely held claim about gratitude that's false is the agency requirement. This comes in two parts: the benefactor requirement, which holds that gratitude can be directed only at benefactors, and the intentionality requirement, 'which limits the range of appropriate benefactors to agents, acting intentionally' (McAleer 2012: 55).

In the next section I examine McAleer's arguments. I will show that any relation propositional gratitude might have to humility cannot demonstrate its importance, that the required proposition that anything with a certain connection to humility is thereby shown to be coherent is assumed rather than argued for, and that the argument against the agency requirement fails, though I will also argue that the agency requirement is false.

\section{McAleer on propositional gratitude}

The best available paper-length defence of the coherence and importance of propositional gratitude comes from McAleer. McAleer (2012) offers an account of propositional gratitude as distinct from targeted gratitude. His aim is to show the plausibility and the moral usefulness of the notion by emphasising its relation to the virtue of humility. McAleer defends the following three claims (McAleer 2012: 55):

(1) 'Propositional gratitude is morally important because of its conceptual connections to humility'

(2) '[T]argeted gratitude to nonagents is likewise coherent and morally important when it expresses humility' 
(3) '[The 'agency requirement'] is false'.

On McAleer's view (1) implies (2), and (2) in turn implies (3). I discuss (1) in Sect. 2.1 and (2) and (3) in Sect. 2.2. Ultimately my position is that McAleer's defence fails, and that (1) and (2) are false, but it will be instructive to examine where things go wrong. (3) is right, but not for the reasons McAleer gives.

\subsection{Gratitude, virtue, debt, and emotion}

Wellman (1999), Carr (2013), Kristjánsson (2015) and others have defended accounts of gratitude that render it as one or another kind of virtue. The usual dialectic opposes this conception to one in which gratitude is understood as a source of obligations or duties, explained by appeal to the language of debt, as in Card (1988) and Lyons (1969).

McAleer makes no effort to argue that gratitude is a virtue. Instead, the move captured in (1) is, having suggested the concept of propositional gratitude, to say something about its links to virtue, specifically the virtue of humility, and to infer things about its moral nature.

Propositional gratitude, and indeed targeted gratitude, may well come along with, or even promote, feelings or expressions of, for example, humility. I won't discuss that here. However, without further argument we are not entitled to claim that a connection to humility justifies classifying a form of behaviour or a mental state as gratitude. Unless we assert in advance that only gratitude could promote, or be an expression of, humility, we would be equally justified in claiming that the connection to humility belongs instead to some species of disappointment, pleasure, or annoyance.

So the observation about humility cannot ground the proposed distinction between targeted and propositional gratitude. It might give us grounds for judging the moral significance of propositional gratitude once we have decided that's what we're looking at, but what we're after here is a defence of the distinction itself. McAleer falls short on that score. We need to motivate the distinction between targeted and propositional gratitude on grounds that do not make appeal to the moral benefits of the distinction.

None of this is to say that propositional gratitude can never be an expression of humility. Or to deny more broadly that encouraging gratitude is a valuable way of promoting various virtues. ${ }^{6}$ I remain neutral on that point, but it's worth saying that McAleer is not alone in arguing for this kind of link between gratitude and (other) virtues. Patrick Boleyn-Fitzgerald makes a case for gratitude to one's enemies as a good means of reducing or avoiding anger (Fitzgerald 1998) and as a means of overcoming avarice and fear (Boleyn-Fitzgerald 2016: 120-121). McAleer (2016) also argues for a structurally similar notion of propositional forgiveness.

\footnotetext{
${ }^{6}$ Moreover, there is a growing academic and popular literature focused on the benefits to individual wellbeing of cultivating a disposition to be grateful for benefits, to see appropriate things $a s$ benefits, and to focus and reflect on occasions on which one is grateful. See for example Watkins et al. (2015), Emmons (2008, 2013) and Wood et al. (2010).
} 
Nevertheless, the fact, if it is a fact, that humility is a good thing, even together with the fact, if it is a fact, that propositional gratitude is a distinctive expression, or promoter, of humility, would not show either that there is such a thing as propositional gratitude, or what propositional gratitude must be like.

At the root of McAleer's argument for gratitude's connection to humility is his claim that ' $[w]$ hen one is grateful that or grateful to, one responds to an unmerited benefit by recognizing it as in fact a benefit, as unmerited' (2012: 60). He says '[t]he targeted gratitude of the detainee who is grateful to his interrogator for not torturing him is misplaced, as is the gratitude of the wife who is grateful to her husband for not beating her: both have a right to not being tortured or beaten; their "benefactors" merely treat them as they are entitled to be treated, and thus do not do them any kindness for which they should be grateful' (2012: 62). Those examples are designed to make targeted gratitude seem ridiculous in those cases. And perhaps it is, but the merit or desert is not the only salient feature. One other feature that might disqualify these agents as legitimate targets of gratitude is the (long) history of malice towards the people concerned.

Indeed, the distraction is obviously removed if we switch to a case in which the benefit is provided by someone other than the oppressor. Suppose a political prisoner is incarcerated by a corrupt regime. The regime persists and the first four dictators deny the political prisoner her freedom. The fifth dictator releases her. She is grateful to the fifth dictator, despite clearly meriting her freedom all along. ${ }^{7}$

Consider also the standard practice of saying 'thank you' to the driver when getting off a bus, or to the shop assistant when taking the goods for which you have just paid. You were entitled in each case to the service you received, but this is compatible with recognising and acknowledging that the person that benefited you was in a position to not help you, and chose to help you, perhaps with a smile. That holds true in cases where your benefactor was bound by a more formal duty to help you: imagine a police officer helping you through the aftermath of a crime, or your parents providing you with food and clothes. They were obliged to do those things, and you were certainly entitled to have those things done, yet gratitude seems appropriate in both cases. Insisting on humility in these cases gets it wrong from all sides.

My aim here is not to dispute that a reaction of humility can ground gratitude, or that gratitude may sometimes be an expression of humility. Many benefits I receive are more than I strictly deserve, and my humble recognition of that fact surely plays a role in generating or reinforcing my love for and gratitude to my benefactors. I only insist that there are also cases in which I receive fully deserved benefits and in which gratitude is wholly appropriate. In such cases, the benefactor did their duty (without necessarily doing anything supererogatory), the beneficiary got no more than they merited or deserved. The beneficiary has a relevant positive attitude towards the benefactor's execution of their duty that isn't humility yet is sufficient to ground gratitude. That positive attitude might be, or be brought about by, appreciation of the social lubrication of civility, the warm glow generated by being

\footnotetext{
7 Thanks to James Heather for suggesting this example.
} 
treated as a human being worthy of recognition and courtesy, or any number of similar things. The beneficiary is, if nothing else, grateful that the benefactor did their duty, and grateful to the benefactor for doing their duty. There is something in what Michael Stein says, talking of volunteers at food banks, that ' $\mathrm{t}$ ] he giving of something calls for the response we identify as gratitude. This is the case whether the recipient is "deserving" or whether the volunteer is "obliged" to give to those in need' (Stein 1989: 245).

Daniel Lyons (1969) argues that the appropriateness of perfunctory thanks for a service 'does not prove that the service was not the beneficiary's right', whilst 'real thanks are due to A for helping B insofar as this help is 'really' praiseworthy', where the gratitude due 'is said to be merely perfunctory when the man to be thanked (a) is expected to wave away the thanks, and (b) is out-of-order if he insists on real gratitude [and t] he gratitude due is real if (a) the person to be thanked may rightly resent the failure to show gratitude, and (b) he would be thought ungracious to wave the thanks away' (Lyons 1969: 92).

My gratitude to the lifeguard that saves me from drowning at the swimming pool seems to me not at all perfunctory. She may be overstepping the mark to insist on any great return of the favour, but if she tried to say 'it was nothing' it would be entirely appropriate for me to insist that it certainly wasn't nothing, even if I was then prepared to leave the matter there in recognition of the fact that she was doing her job, I was entitled to the help, and so on.

Lyons models gratitude on debt and this is the source of the problem here. This is the traditional alternative to modelling it on virtue, which I also reject, but a third way of modelling it as grounded in an episodic emotion makes better sense of the phenomenology of, for example, the lifeguard case. I certainly feel an appropriate positive inclination to the lifeguard's saving of my life. The debt formally incurred is not large in this case, in part because it was the lifeguard's job to help me, but the thanks would be heartfelt, not perfunctory. If, at some point in the future, I found myself in a position to help the lifeguard out of some difficulty and I declined to do so, reasoning that I was not required to by any duty, and she had in any case not done any more for me than she was required to by her contract, I would be to some extent morally deficient. For more on the episodic emotion of gladness that I argue underlies all instances of gratitude, see Sect. 3.

The fact that very real and deep feelings of gratitude - and even, as discussed in for instance Wellman (1999: 287), Camenisch (1981: 6), and Gulliford et al. (2013: passim) a real desire to return the favour when necessary or appropriate-can accompany a situation in which no very great formal debt is incurred is itself evidence that debt is not an appropriate model for understanding gratitude. In Sect. 3 I will show how episodic emotion, rather than duty, and rather than the virtue constituted by a disposition to feel certain emotions in certain circumstances, can ground gratitude.

We can further reinforce the idea that targeted gratitude is possible and can be appropriate even when the benefit is fully deserved by broadening the group of potential benefactors beyond the case in which the benefit amounts to someone's duty. Suppose I am a world-class poet but I have become, wholly undeservedly, 
personally very unpopular. ${ }^{8}$ I deserve, in some reasonable sense, to be considered for the prestigious poetry prize in a competition organised by the Michael Gove Institute for the Literary Arts. My work certainly merits it but my unpopularity means that no one is prepared to nominate me. If an expectation is realistic if and only if there is a fair chance of the expected conditions coming to obtain, and reasonable just in case the conditions coming to obtain would constitute an improvement in the moral order of things, we might say I have no realistic expectation, given the limitations imposed by living in an unjust world, of my work being considered, even though, since justice would bring with it the right and proper recognition of my genius, I may have a perfectly reasonable expectation that it ought to be considered. ${ }^{9}$ Suppose you nominate me and work hard to get my work accepted and overcome the stigma, even though you know that you may in turn become unjustly unpopular in the process. Absolutely anyone could have done this for me; nevertheless I had no realistic expectation of anyone doing so, and no one but you did. The benefit doesn't go beyond what is merited by the quality of my work; indeed the injustice of my poor reputation perhaps means that I am entitled to be rehabilitated, and my nomination doesn't exceed what it was reasonable for me to expect, but I may perfectly understandably be grateful to you since I had no claim on you in particular to help me in this way.

The lifeguard case strongly suggests that gratitude shouldn't be modelled on debt. Though a tendency to gratitude, or a virtue of gratefulness, may be cultivated and may be morally praiseworthy or beneficial, it is nevertheless clear that someone may genuinely be grateful on an isolated occasion surrounded by a sea of curmudgeonly miserableness. This brings us back to emotion. But what sort of emotion? My claim is that propositional gratitude shares features in common with, but goes a little way beyond, being glad that something is the case.

McAleer argues that "what distinguishes gratitude from merely being glad or pleased is [...] gratitude's being an expression of humility' (2012: 61). I appreciate the need to pin the distinction on something, but I don't think it is adequately marked by appeal to humility. Section 3 offers an alternative way of marking it. Before we trace the connection between gratitude and gladness and draw together a definition, we need to show how we may dispense with the agency requirement, the supposed constraint that gratitude can only occur when an agent has benefited us by their intentional action. I will argue that gratitude to nonagents is illegitimate and that apparent cases are better explained as mistaken, perhaps unconscious, attributions of agency to nonagents, but that the coherence of propositional gratitude is enough to rid us of both parts of the agency requirement.

\footnotetext{
${ }^{8}$ I'm grateful to James Lenman for the gist of this example.

9 My thanks to an anonymous referee for suggesting this helpful way of putting the point.
} 


\subsection{The agency requirement}

The agency requirement is divisible into the intentionality requirement and the benefactor requirement. That is, it says that gratitude has to be directed to a benefactor, and that benefactor has to be acting intentionally in providing the benefit. McAleer (2012: 55-56) attributes something like the agency requirement to, among others, McConnell (1993), Berger (1975), and Weiss (1985). He rejects the agency requirement, arguing that the possibility of propositional gratitude is a reason to reject the intentionality requirement, and the possibility of targeted gratitude to nonagents is a reason to reject the benefactor requirement.

Propositional gratitude is gratitude in which there is no benefactor, and so of course no benefactor acting intentionally. So the intentionality requirement rules out propositional gratitude. Or, conversely, the possibility of propositional gratitude refutes the intentionality requirement. I agree with McAleer that we ought to reject the agency requirement, but there is no need to invoke targeted gratitude to nonagents to dispel the benefactor requirement: propositional gratitude does all the work we need done. It undermines the benefactor requirement, since it is a form of gratitude in which there is no benefactor. If no benefactor is required for gratitude, the question of whether one's benefactor was acting intentionally doesn't arise, so the possibility of propositional gratitude undermines both parts of the agency requirement.

Even absent the possibility of propositional gratitude, the intentionality requirement is too strict and under-motivated since one may sincerely say such things as 'you weren't even aware that you were helping, but I've been grateful to you ever since'. Gratitude may well be legitimate and warranted in such a case.

We don't need to appeal to the possibility of targeted gratitude to nonagents in the argument against the agency requirement, and we can go further and dispense with it altogether. Recall the second of the claims to which McAleer is committed:

(2) '[T]argeted gratitude to nonagents is [...] coherent and morally important when it expresses humility' (2012: 55)

The punctuation in (2) suggests that the coherence, and not just the moral importance, of targeted gratitude to nonagents is supposed to be tied to the expression of humility. I argued above that the expression of humility, or of any other virtue, is not an essential part of either targeted or propositional gratitude. Instances of gratitude needn't be expressions of humility, and expressions of humility needn't be instances of gratitude. If targeted gratitude to nonagents is a concept we need, either to make sense of our gratitude practices or more narrowly to explain why the agency requirement is unmotivated, and if targeted gratitude to nonagents is coherent only when it is an expression of humility, I will have been too hasty in dismissing the connection to humility above as unnecessary for gratitude. I don't think I was too hasty, because targeted gratitude to nonagents is not a concept we need, and indeed there is a better explanation available for putative cases.

People can and do say that they are grateful to mountains, or to the sun for shining, or to trees for shading us, but we are not compelled to take such cases at 
face value since they are at least as plausibly thought of as disguised attributions of agency to nonagents towards which we then (mis)direct gratitude.

Targeted gratitude requires, in a way that will be precisely spelt out in Sect. 3.3, someone we take to be the author of some circumstances that we consider beneficial to us. If we tried, using a vocabulary containing only targeted gratitude, to understand a case of being positively inclined towards some trees on account of the shade they afforded us from the sun when we sat down to rest, our options would be to dismiss the feeling that what we were experiencing was some species of gratitude, or attribute agency to trees. Neither might strike us as acceptable if an alternative could be found. The emotional phenomenology is similar enough to cases of being grateful to undisputed agents for us to report feeling grateful, and yet we feel uncomfortable, when it comes down to it, about attributing (the right kind of) agency to trees. But expand our vocabulary to admit the language of propositional gratitude and we can satisfy both of our inclinations. In the circumstances described, we are grateful that the trees afforded us some shade when we needed it, and that the mountain inspired us to poetry as we sat under the trees in the sun.

Consider McAleer's example: a group of miners being grateful to the mountain 'for all the wealth she's given [them]' and feeling that 'the least [they] can do' is to 'close her wounds' (2012: 62). McAleer says, 'since mountains are not agents, the agency requirement renders such gratitude not obligatory. However, the friends of the agency requirement will not regard the miners' restoring the mountain as supererogatory; it will be regarded as incoherent, expressing a sentiment that is noble, perhaps [...] but fundamentally confused and philosophically indefensible, because it violates the intentionality (and thus the agency) requirement' (2012: 63). But McAleer thinks gratitude to the mountain is legitimate, because it 'is grounded in the humility it expresses' and indeed 'is required by the virtue of humility' (2012: 63). Boleyn-Fitzgerald (2016) also defends gratitude to things arguing for both its intrinsic and its instrumental value.

But consider the alternative. The attribution of agency to the mountain is very nearly on the surface here: 'all the wealth she's given': that's agential language for a start. Talk of 'closing her wounds' seems anthropomorphic, or perhaps metaphorical. Animals, and possibly plants, but not mountains, have literal wounds; agents give us things. Talk in these terms suggests the miners in McAleer's example were already primed to think of the mountain as something towards which it would be proper to feel sympathetic, pitying, or grateful. Those that believe that gratitude is limited to cases involving agents as benefactors are most likely to read the miners' behaviour as evidence of the attribution of agency to the mountain, however unaware the miners may be that this is what they were doing and notwithstanding the sincerity of their reports of feelings of gratitude towards what they consciously consider a nonagent.

The miners may be grateful that the mountain has delivered mineral wealth, and there may be several sorts of reasons for wanting to restore the mountain once they have finished mining: aesthetic, environmental, ecological, or health and safety. Humility may perhaps merit inclusion on that list, and perhaps restoring the mountain would be required by humility as McAleer suggests, but the purported 
gratitude to the mountain is more convincingly explained in other terms, and gratitude to the mountain cannot be required by any of the virtues if the mountain is not an agent and so not a proper target of directed gratitude at all.

The rejection of the agency requirement that I'm proposing here, which ignores the prospect of targeted gratitude to nonagents, relies correspondingly heavily on the possibility of propositional gratitude. But note that McAleer's rejection of the agency requirement does that, too: he needs propositional gratitude to undermine the intentionality requirement. McAleer offers one further way of motivating thinking of what we're calling 'propositional gratitude' as genuine gratitude. He illustrates it by considering a story from Marcia Baron in which she says '[a]cts of heroism are typically thought of as off in a realm unto themselves, and it is no wonder that they are. We admire the qualities that enable a person to dive in midwinter into the Potomac in an effort to save the victims of a plane crash. And we are grateful that people with such qualities (courage, willingness to risk their lives to help others, etc.) exist' (Baron 1995: 46, quoted in McAleer 2012: 57).

McAleer's suggestion is that targeted gratitude and propositional gratitude will be shown to both be instances of gratitude if we, as he puts it, 'semiformally' render instances of the two putative types. The idea is that the logical form of the two kinds of sentences will be shown to be different and that this will allow us to show how the same 'gratitude operator' is at work in each case, giving different results according to its scope.

In the Potomac case as Baron presents it, McAleer recommends giving a gratitude operator wide scope over an existential quantifier binding a variable to which we attribute the predicate 'is a hero'. He suggests that the targeted gratitude that we might aim at such a hero would best be rendered by giving the existential quantifier wide scope over the gratitude operator. If this is right, the difference between the two putative forms of gratitude is one of scope rather than semantics: the targeted and the propositional form are both gratitude, and the difference is one of the role gratitude plays when there is no benefactor at which it's directed. We have one kind of gratitude, 'sometimes aimed at targets, sometimes not' (McAleer 2012: 57). If this move works, there is only one sort of gratitude after all, and it covers cases that the agency requirement was designed to rule out. This, if compelling, at least suggests a comprehensive approach to the concept of gratitude rather than arbitrarily isolating some sub-concept, and addresses Kristjánsson's (2015: 503) concern that philosophers tend not to be talking about the 'umbrella concept', even when they apparently think they are. However, in the way McAleer sets the cases out, the variant phrases 'grateful that' and 'grateful to' still appear in the semiformal translations. I suspect that is doing more work than he acknowledges.

To my ears, the targeted case is at least as well rendered by defining a three-place relation '...is grateful to... for...'. Since the propositional case may also be rendered in a similar way, but by defining a different relation, this time the twoplace relation '.. is grateful that...', there is at least as much reason, based on formalisations, to think that there are two sorts of gratitude here. Both, moreover, would still be genuine forms of gratitude, and the agency requirement would still be undermined. 
McAleer's own introduction employs the phrases 'A's being grateful that $p$ ' and 'A's being grateful to B for $x$ '. You can almost see the dyadic and triadic relations on the surface. So we can say, in the propositional case, 'there exists an $x$ such that B is grateful that $x$ is a hero' and for targeted gratitude we can say that, 'there exists an $x$ such that $\mathrm{B}$ is grateful to $x$ for acting heroically'. On the strength of that, the difference between targeted gratitude to someone for acting heroically and propositional gratitude that someone is a hero would be shown to be a difference in predicate rather than a difference in scope.

McAleer's arguments are not enough to persuade us that propositional gratitude is a phenomenon distinct from targeted gratitude, even if we consider them as only two ways of 'aiming the same kind of gratitude', where both ways involve the same gratitude operator and the difference is one of scope. His discussion of logical form is not in the end compelling, because equally plausible arguments deliver a radically different result. ${ }^{10}$ If we are to defend the distinction and motivate the inclusion of propositional gratitude in our account of gratitude we need a way of showing that propositional gratitude is not the same as targeted gratitude, that it is nevertheless enough like it to be regarded also as a kind of gratitude, and that it is not the same as mere gladness. The next section addresses this need.

\section{Propositional gratitude and gladness}

If, as I suggested in Sect. 1, we are to analyse gratitude as grounded in an emotional response to perceived benefit, we need a systematic way to distinguish it from 'mere' gladness. We have a reasonable intuitive grasp of the scope of the term 'gladness', and it's diffuse enough to cover cases in which we would resist saying we were grateful for anything. One option is to say, in the spirit of the benefactor requirement, that gratitude is the emotion felt towards a benefactor when that benefactor has brought about one's circumstances. In the remaining cases, including all those in which no benefactor played a role, we could say one was glad, but not grateful.

However, as McAleer (2012), Walker (1981), Fitzgerald (1998), Card (1988) and others have in various ways argued, some cases of gladness are (also) cases of propositional gratitude. I share this view and I will defend it by distinguishing between two kinds of cases of gladness: those in which one would have been grateful to an agent for bringing about the circumstances had there been such an agent, and those in which one would not have been grateful to such an agent. The former are cases of propositional gratitude, the latter cases of mere gladness.

In Sect. 3.1 I deal with an argument presented in terms of 'appreciation' rather than gladness, and show that it fails to resolve the matter we're interested in. Recall that Kristjánsson (2015), drawing on Gulliford et al. (2013), argues that putative cases of propositional gratitude are better understood as cases involving appreciation in this sense. In Sect. 3.2 I deal with gladness itself, and in Sect. 3.3 I outline a definition of gratitude incorporating both targeted and propositional components.

\footnotetext{
$\overline{{ }^{10} \mathrm{I} \text { am grateful to an anonymous referee for urging a clarification }}$ on this point.
} 


\subsection{The concept of appreciation}

'Appreciation' is the name Adler and Fagley (AF) (2005) give to a collection of emotional, perceptual, and dispositional features. They identify eight aspects, including gratitude. Appreciation is 'acknowledging the value and meaning of something — an event, a person, a behaviour, an object—and feeling a positive emotional connection to it' (2005: 81). Kristjánsson (2015) argues that where we might see propositional gratitude, there is only appreciation. The question is,

whether the concept of gratitude incorporates the extension of [...] appreciation as a subset, or whether those are better understood as two distinct concepts. I may appreciate life but does it mean that I am grateful for it? There are two senses of gratitude vying for allegiance here, sufficiently distinct to be called different concepts, not only different conceptions, of gratitude. One characterises gratitude as an essentially social emotion of a specific attitudinal relationship to a benefactor; the other as the habitual focusing on and appreciation of life's positive benefits. As I am interested in carving out a virtue-concept of gratitude and virtues are inherently social, I rely on the triadic understanding in what follows (Kristjánsson 2015: 501).

There are a number of problems with this. First, AF see gratitude as just one of eight aspects of appreciation, one which 'refers to noticing and acknowledging a benefit that has been received, whether from another person or a deity' (2005: 83). So gratitude as an aspect of appreciation is firmly triadic in its conception. As they have gratitude as a triadic aspect of the supposedly dyadic concept of appreciation (supposed, at any rate, by Kristjánsson: AF are not explicit on this point themselves) Kristjánsson's own question ought to be whether gratitude, of the triadic type in which he is interested, is incorporated in the concept of appreciation, rather than the other way round. AF's paper seems to suggest that although one might not be grateful for one's life in a dyadic sense, one may very well be grateful to the person or persons that brought one's life about, and that would count as an instance of appreciation.

Up to a point, appreciation looks like it could be a candidate either for what I am calling 'propositional gratitude' or what I am calling 'mere gladness', being as it is a collection of positive attitudes towards one's circumstances. Nevertheless, in the way it is set out, AF's concept of appreciation simply begs the question at issue in this paper and assumes that gratitude is triadic. They are careful to allow the possibility that one's benefactor may be a deity, but that is still very much a thirdparty provider of benefits. Kristjánsson's appeal to AF's concept of appreciation as a candidate for the putative dyadic version of gratitude that we're calling 'propositional' is odd in this context. Appreciation has gratitude as a component, rather than the other way round, and the gratitude that it has as a component is triadic, and not the sort of dyadic relation we're looking for. Fagley later reasserts this, describing gratitude as '[f]eeling grateful to a benefactor for help, support, or opportunities' (Fagley 2016: 71). Gladness, by contrast, in the sense in which I am using it here, which I think accords with conventional English usage, is a dyadic concept. One is glad that $x$. 
As it happens, I agree with AF to the extent that I think triadic, targeted, gratitude, gratitude to a supposed benefactor, is an aspect of a broader concept. I argue that propositional gratitude underpins every case of directed gratitude, as well as sometimes existing without directed gratitude. Gladness is broader still, being present in all cases of directed gratitude, all cases of propositional gratitude that are not also cases of directed gratitude, and some further cases that I'm calling 'mere gladness'. It is beyond the scope of this paper to consider whether there are any relevant or interesting similarities between gladness and appreciation. For now I will just note that the terminology AF use and the assumptions they make about gratitude are unhelpful to my project, so I will pass on.

\subsection{Gladness}

Let 'gladness' name a positive emotional response to circumstances. I don't want to stipulate any particular normative component, and the precise details of the emotion may vary between cases. I may be glad, for one reason or another, that term has just finished, that an accident at sea was prevented from becoming a disaster, that I got tickets to see King Crimson, and so on. Given this broad range, the question for the defender of propositional gratitude is why all putative cases of propositional gratitude can't just be marked down as cases of gladness and let's have done with it.

Consider this example: a maritime disaster is averted. Hundreds of people have been spared from drowning when a cruise liner hit a reef and began taking on water. Left to itself the ship would have sunk. However, a dead porpoise got stuck in the hole and the ship remained afloat. I hear about this and I am glad.

Keep those details of the case fixed and then consider the following variants. (i) the porpoise just happened to float into place and I know no one involved; (ii) the porpoise just happened to float into place and my niece is saved from drowning; (iii) Peter Singer positioned the porpoise and my niece is saved from drowning; (iv) Peter Singer positioned the porpoise and I know no one involved.

I would be glad in all four cases. It's good when people are saved from drowning. Let's start with the cases involving an agent. In (iv) I think my response goes no further than gladness. The good thing is not connected to me in the right way to count as a benefit to me and so to inspire gratitude; it's just ordinarily none of our business to be grateful to people for benefiting strangers. In a case where someone benefits strangers to help us out in our specifically defined responsibility of benefiting strangers, we may of course be grateful to them, but in that case the gratitude is prompted in part by a benefit to us: the removal of part of our workload, or the achievement of one of our goals. Otherwise our positive appraisal of someone helping people that are strangers to us would generate only approval, awe, love, and so forth. (We may on occasion, of course, be grateful to someone for doing something that made us glad, perhaps if we felt in particular need of good news after a dismal spell. That would be another instance of the actions of the stranger being of benefit to us, and so doesn't change the present point.)

In a case where strangers who it was our responsibility to help are helped by the uncoordinated bobbing of a dead porpoise we may be grateful that they have been 
helped, because we are appropriately involved in their situation: at the very least it saved us a job.

There may be cases in which the personal involvement in helping the strangers was what was important to us, and we resent the interference of Peter Singer or the porpoise. In such cases we are not glad-and therefore not grateful - that the dead porpoise helped the strangers, and nor are we glad that Peter Singer helped the strangers, since we wanted to benefit by doing it ourselves and we have been denied this. But anyone disappointed in such a situation should have a good look at their motivations. There is a view that holds that the suffering of the needy is something for which to be grateful since it provides us with opportunity to display compassion. So we find Boleyn-Fitzgerald defending what he says is the Buddhist notion of gratitude to those one helps on the grounds that they provide us with such an opportunity: '[b]ecause compassion is thought to be immensely beneficial to those who feel it, it is considered appropriate to feel grateful to those who cause one's compassion' (Fitzgerald 1998: 127). I'm with Kristjánsson when he says '[h]owever commendable compassion is when it appropriately occurs, it would be better if the occasions which call for it were fewer and farther between' (Kristjánsson 2015: 507).

However, in (iii) I am grateful to Peter Singer for positioning the porpoise because he was responsible for saving my niece. This gives us reason to say that in (ii) had someone nudged the porpoise into place I should have been grateful to that person, but not so in (i).

This intuitive difference between (iii) and (iv) and the counterfactual occasion for gratitude in (ii) but not (i) gives us a distinction crying out for a label. (i) and (iv) are cases of just gladness; (ii) is a case also of propositional gratitude; (iii) is a case also of targeted gratitude.

I am glad in a range of cases. Of those cases, I am grateful-that in all and only those cases in which I would have been grateful-to had there been an appropriate agent to serve as a target. And of those cases I am grateful-to in all and only those cases in which there actually was such an agent.

\subsection{A two-part definition of gratitude}

We can assay a definition at this point.

Targeted Gratitude $=\mathbf{d f}$

A person, $p$, is grateful-to $a$ (for $x$ ) iff:

(1) $p$ believes that $x$ is a benefit to $p$;

(2) $p$ is glad that $x$ is the case;

(3) $p$ believes that $a$ brought about $x$, or played a relevant role in bringing about $x$;

(4) $p$ does not believe that $a$ has any disqualifying negative intentions or attitudes.

Propositional Gratitude $\mathbf{=} \mathbf{d f}$

$p$ is grateful-that $x$ iff:

(1) and (2), plus 
(5) had $p$ taken $a$ to have brought about $x$, or played a relevant role in bringing about $x$, and not taken $a$ to have any disqualifying negative intentions or attitudes, $p$ would have been grateful to $a$.

I treat targeted gratitude first since it is explanatorily more basic. Propositional gratitude is metaphysically more basic in the sense that it is entailed by, but does not entail, targeted gratitude. That is, propositional, but not targeted, gratitude can exist by itself. A person alone in the universe, without the company of human or other agents, unwatched by gods, and under no illusions about their solitude could properly be described as, for example, grateful that the rain held off for the harvest. Circumstances have conspired to make targeted gratitude impossible for this person, and they may lack the idea of it altogether. Nevertheless we, looking in, can identify their propositional gratitude and correctly describe it as such. The counterfactual in (5) now takes us to a different possible world, in which there are other agents available to potentially be grateful to, but the conditional still has the force it always had in the definition given here. The explanatory order above comes about because targeted gratitude has historically been by far the better-understood notion, and what I have said about it here is rather less controversial than what I have said about propositional gratitude.

Let us examine the components of the definition. Clause (1) rules out maritime catastrophe versions (i) and (iv) in which there is insufficient connection between the good thing and my interests. In general, it rules out cases in which the situation over which $p$ might feel glad is not related to $p$ in appropriate ways. So $a$ will be a target of the gratitude of $p$ when $p$ takes $a$ to have acted to help $p$ personally, whether $a$ does so intentionally, and, if so, whether $a$ succeeds or fails, or does so incidentally to some other non-disqualifying activity; $a$ will also be a target of the gratitude of $p$ when $a$ acts in such ways so as to benefit someone related appropriately to $p$, for instance a friend or a relative.

But $a$ will not be a target of the gratitude of $p$ if the benefit $a$ produces benefits only (some of) those to whom $p$ is not appropriately related; $a$ will also not be a target of the gratitude of $p$ if $a$ benefits $p$ but does so, either accidentally or deliberately, in the course of trying to cause harm to $p$, either at the time of acting or in the longer term. These are the relevant disqualifying features that the action of $a$ might have. Consider a prisoner in a concentration camp waiting in line to be shot. ${ }^{11}$ He begs to be taken first so that he should not have to watch friends and family being murdered. The guard, out of malice, puts him to the back of the queue. As a result he survives the day and overnight the camp is liberated and the man gets out alive. Suppose (though of course this is not straightforward) the man is glad to have survived. Had he taken someone to have brought that about in a nondisqualifying way he would have been grateful to them, as indeed he may be to the liberating army. The guard played an equally essential causal role in his survival but we do not want to say he should be grateful to the guard. The malice is disqualifying.

${ }^{11}$ I owe this example to Harry Lesser. 
The belief operator in (1) is important, since if $x$ is not a benefit but $p$ thinks it is, then $p$ might still be grateful-that $x$, though this propositional gratitude would perhaps count as somehow badly motivated. Badly motivated gratitude should still count as gratitude for purposes of a definition.

Clause (2) rules out any case in which I am indifferent or hostile to the situation in which I find myself (even if, by some objective measure, it is a situation from which I might count as having benefited). Taken together (1) and (2) do not rule out cases in which I am grateful to someone for putting me in a difficult situation on the grounds that it allows some kind of personal development. I'm happy to allow those as genuine cases of gratitude. (4), however, rules out any such case in which I also take the agent to be hostile to me, motivated by distasteful intentions, and so forth.

Clause (3) does not require that $a$ brought about $x$, only that $p$ believes $a$ brought about $x$. My gratitude to you for feeding my cat whilst I was on holiday without my asking you to may be short-lived if I take it to have been misplaced when I subsequently discover that in fact he fended quite nicely for himself by culling the local sparrows, but it would have been quite genuine while it lasted.

Clauses (3) and (4) together allow that $p$ can be grateful to $a$ for simply passing by and unknowingly scaring away muggers.

Clauses (1), (2), and (5) together allow for cases in which $p$ is grateful for the self-development opportunities afforded by an apparently bad situation but doesn't direct that gratitude towards $a$ because either $p$ doesn't take $a$ to have been the cause of $x$, or $p$ takes $a$ to have brought about $x$ in the course of abusing $p$ in some way. (1), (2) and (5) are also clearly satisfied when (1)-(4) are satisfied.

Clause (5) appeals to negative intentions and attitudes generally, rather than only those directed at $p$. This includes those directed at $p$ as a subset, but is deliberately left wider to allow for cases in which $p$ fails to be grateful to $a$, despite $a$ having only the best regard for $p$ as an individual, on the grounds that $a$ has some wider plan of which $p$ disapproves. For instance $p$ might very well fail to be grateful to $a$ for sparing $p$ some detrimental treatment on the grounds of $p$ 's race, of which $a$ wholeheartedly approves, as part of a systematic disadvantaging of people of other races. There is a clear narrow sense in which this is of benefit to $p$, but it is recognised by $p$ to be part of a wider programme that is morally unacceptable, so $p$ is not grateful to the agent of its realisation. Whether $p$ would be grateful that their situation was thus-and-so might depend on whether $p$ judged $x$ to be a genuine benefit, given its all-things-considered reprehensibility. It is also possible for $p$ to be grateful-that $x$ and grateful to $a$ for bringing about $x$ and later stop being grateful to $a$ for bringing about $x$ and even stop being grateful that $x$ once the full details of the case emerge.

In related kinds of case we can see how something of our gratitude remains even as our attitude changes in response to new evidence. We discover that Elspeth was genuinely trying to kill us so we come to see her sword attack in a very different light and are no longer grateful to her for her efforts, though we remain grateful that our hiccups were cured by the surprise. We remain grateful to Rory for his genuine and sincere efforts to repair our brakes even as we resign ourselves to our fate as our bicycle slams into a tree. It may be that we acknowledge this lingering gratitude only after the excitement has died down. 
The two parts of the definition show that propositional gratitude is entailed by, but does not entail, targeted gratitude. Both targeted and propositional gratitude entail gladness though gladness, as I have argued, does not entail either form of gratitude.

It should be clear that we don't import the intentionality requirement with this definition. We insist throughout on a focus on the attitude of $p$, requiring only that $a$ lack, as far as $p$ can tell, any disqualifying attitude, not that they have a beneficent one, or even that they have noticed the existence of $p$ at all.

\section{Conclusions}

The definition defended here makes no mention of debts. Whilst allowing that a grateful person might wish in some sense to return the favour, the existence of gratitude doesn't depend on it. Neither does gratitude rely on a settled character trait of gratefulness or a tendency to be grateful wherever possible. I don't wish to rule out the possibility of a virtue of gratitude based on such a tendency, or to deny that gratitude can go hand-in-hand with indebtedness, but neither is constitutive of gratitude simpliciter and there is value in getting the basic definitions sorted out before we start trying to apply them.

So we have a broad theory of gratitude, unifying the dyadic and triadic components, in which gratitude is modelled on episodic emotion and in which propositional gratitude has a central part to play.

Acknowledgements I'm grateful, for one thing and another, to Anthony Fisher, Kendall Fisher, James Heather, Craig Herbertson, Gayle Impey, Anneli Jefferson, Paul Knights, James Lenman, audiences of two earlier versions of this paper, and an anonymous referee for this journal. Thank you to my graduate students in Manchester for their healthy scepticism. Particular thanks to John William Devine, and Ema Sullivan-Bissett, without whom the present version of the paper would not exist. I would like to honour the memories of Patrick Boleyn-Fitzgerald and Harry Lesser with my gratitude for detailed and formative discussion. Finally, thank you to Terrance McConnell, who very kindly sent me a copy of his excellent book.

Open Access This article is distributed under the terms of the Creative Commons Attribution 4.0 International License (http://creativecommons.org/licenses/by/4.0/), which permits unrestricted use, distribution, and reproduction in any medium, provided you give appropriate credit to the original author(s) and the source, provide a link to the Creative Commons license, and indicate if changes were made.

\section{References}

Adler, M. G., \& Fagley, N. S. (2005). Appreciation: Individual differences in finding value and meaning as a unique predictor of subjective well-being. Journal of Personality, 73, 79-114.

Aquinas, T. (1964). Summa theologiae. London: Eyre and Spottiswoode.

Baron, M. (1995). Kantian ethics (almost) without apology. Ithaca, NY: Cornell University Press.

Berger, F. (1975). Gratitude. Ethics, 85, 298-309.

Berkovski, Y. S. (2014). Gratitude, self-interest and love. Philosophia, 42, 645-664.

Boleyn-Fitzgerald, P. (2016). Gratitude towards things. In D. Carr (Ed.), Perspectives on gratitude: An interdisciplinary approach (pp. 112-125). London: Routledge. 
Camenisch, P. F. (1981). Gift and gratitude in ethics. The Journal of Religious Ethics, 9, 1-34.

Card, C. (1988). Gratitude and obligation. American Philosophical Quarterly, 25, 115-127.

Carr, D. (2013). Varieties of gratitude. Journal of Value Inquiry, 47, 17-28.

Carr, D. (Ed.). (2016). Perspectives on gratitude: An interdisciplinary approach. London: Routledge.

Emmons, R. A. (2008). Thanks! How practicing gratitude can make you happier. New York: HoughtonMifflin.

Emmons, R. A. (2013). Gratitude works! A 21-day program for creating emotional prosperity. San Francisco: Jossey-Bass.

Fagley, N. S. (2016). The construct of appreciation. In D. Carr (Ed.), Perspectives on Gratitude: An interdisciplinary approach (pp. 70-84). London: Routledge.

Fitzgerald, P. (1998). Gratitude and justice. Ethics, 109, 119-153.

Gulliford, L., Morgan, B., \& Kristjánsson, K. (2013). Recent work on the concept of gratitude in philosophy and psychology. Journal of Value Inquiry, 47, 285-317.

Hewitt, J. W. (1924). The development of political gratitude. Transactions and Proceedings of the American Philological Association, 55, 35-51.

Hobbes, T. (1998). On the citizen. Cambridge: CUP.

Kant, I. (1967). Critique of practical reason. London: Longmans.

Kant, I. (2000). Groundwork of the metaphysics of morals (M. Gregor, Ed.). Cambridge: CUP.

Klosko, G. (1989). Political obligation and gratitude. Philosophy \& Public Affairs, 18, 352-358.

Klosko, G. (1991). Four arguments against political obligations from gratitude. Public Affairs Quarterly, $5,33-48$.

Knowles, D. (2002). Gratitude and good government. Res Publica, 8, 1-20.

Kristjánsson, K. (2015). An Aristotelian virtue of gratitude. Topoi, 34, 499-511.

Lyons, D. (1969). The odd debt of gratitude. Analysis, 29, 92-97.

McAleer, S. (2012). Propositional gratitude. American Philosophical Quarterly, 49, 55-66.

McAleer, S. (2016). Are gratitude and forgiveness symmetrical? In D. Carr (Ed.), Perspectives on gratitude: An interdisciplinary approach (pp. 85-96). London: Routledge.

McConnell, T. (1993). Gratitude. Philadelphia: Temple University Press.

Nietzsche, F. (1994). On the genealogy of morality (C. Diethe, Trans. K. Ansell-Pearson, Ed.). Cambridge: CUP.

Paley, W. (1822). The principles of moral and political philosophy. London: Baldwin, Cradock and Joy.

Roberts, R. C. (2014). Cosmic gratitude. European Journal for Philosophy of Religion, 6, 65-83.

Seneca, L. A. (2001). De Beneficiis. Seneca: Moral essays, volume III (J. W. Basore, Trans. Loeb Classical Library). Cambridge, MA: Harvard University Press.

Seneca, L. A. (2006). On benefits. In Epistles 66-92 (R. M. Gummere, Trans. Loeb Classical Library) (pp. 218-241). Cambridge, MA: Harvard University Press.

Shaw, J. (2013). Gratitude, self-assessment, and moral community. Journal of Value Inquiry, 47, 407-423.

Simmons, A. J. (1979). Moral principles and political obligations. Princeton, NJ: Princeton University Press.

Stein, M. (1989). Gratitude and attitude: A note on emotional welfare. Social Psychology Quarterly, 52, 242-248.

Stout, G. F. (1927). The Groundwork of psychology. London: University Tutorial Press.

Strawson, P. F. (1974). Freedom and resentment. In Freedom and resentment and other essays (pp. 1-25). London: Methuen.

Swinburne, R. (1989). Responsibility and atonement. Oxford: OUP.

Von Tevenar, G. (2006). Gratitude, reciprocity and need. American Philosophical Quarterly, 43, 181-188.

Walker, A. D. M. (1981). Gratefulness and gratitude. Proceedings of the Aristotelian Society, 81, 39-55.

Walker, A. D. M. (1988). Political obligation and the argument from gratitude. Philosophy \& Public Affairs, 17, 191-211.

Walker, A. D. M. (1989). Obligations of gratitude and political obligation. Philosophy \& Public Affairs, 18, 359-364.

Watkins, P. C., Uhder, J., \& Pichinevskiy, S. (2015). Grateful recounting enhances subjective well-being: The importance of grateful processing. The Journal of Positive Psychology, 10, 91-98.

Weiss, R. (1985). The moral and social dimensions of gratitude. Southern Journal of Philosophy, 23, 491-501. 
Wellman, C. H. (1999). Gratitude as a virtue. Pacific Philosophical Quarterly, 80, 284-300.

Wood, A. M., Froh, J. J., \& Geraghty, A. W. (2010). Gratitude and well-being: A review and theoretical integration. Clinical Psychology Review, 30, 890-905.

Publisher's Note Springer Nature remains neutral with regard to jurisdictional claims in published maps and institutional affiliations. 